\title{
Model of genetic and environmental factors associated with type 2 diabetes mellitus in a Chinese Han population
}

\author{
Zheng Li', Cheng-yin Ye', Tian-Yu Zhao ${ }^{1,2}$ and Lei Yang ${ }^{1 *}$ (D)
}

\begin{abstract}
Background: Type 2 diabetes mellitus (T2DM) is a metabolic disorder which accounts for high morbidity and mortality due to complications like renal failure, amputations, cardiovascular disease, and cerebrovascular events.

Methods: We collected medical reports, lifestyle details, and blood samples of individuals and used the polymerase chain reaction-ligase detection reaction method to genotype the SNPs, and a visit was conducted in August 2016 to obtain the incidence of Type 2 diabetes in the 2113 eligible people. To explore which genes and environmental factors are associated with type 2 diabetes mellitus in a Chinese Han population, we used elastic net to build a model, which is to explain which variables are strongly associated with T2DM, rather than predict the occurrence of T2DM.

Result: The genotype of the additive of rs964184, together with the history of hypertension, regular intake of meat and waist circumference, increased the risk of T2DM (adjusted $\mathrm{OR}=2.38, p=0.042$; adjusted $\mathrm{OR}=3.31, p<0.001$; adjusted $\mathrm{OR}=1.05, p<0.001$ ). The $\Pi \mathrm{g}$ genotype of the additive and recessive models of rs 12654264 , the CC genotype of the additive and dominant models of rs2065412, the $\Pi$ genotype of the additive and dominant models of rs4149336, together with the degree of education, regular exercise, reduced the risk of T2DM (adjusted $\mathrm{OR}=0.46, p=0.017$; adjusted $\mathrm{OR}=0.53, p=0.021$; adjusted $\mathrm{OR}=0.59, p=0.021$; adjusted $\mathrm{OR}=0.57, p=0.01$; adjusted $\mathrm{OR}=0.59, p=0.021$; adjusted $\mathrm{OR}=0.57, p=0.01$; adjusted $\mathrm{OR}=0.50, p=0.007$; adjusted $\mathrm{OR}=0.80, p=0.032$ ) .

Conclusion: Eventually we identified a set of SNPs and environmental factors: rs5805 in the SLC12A3, rs 12654264 in the HMGCR, rs2065412 and rs414936 in the ABCA1, rs96418 in the ZPR1 gene, waistline, degree of education, exercise frequency, hypertension, and the intake of meat. Although there was no interaction between these variables, people with two risk factors had a higher risk of T2DM than those only having one factor. These results provide the theoretical basis for gene and other risk factors screening to prevent T2DM.
\end{abstract}

Keywords: Type 2 diabetes mellitus, Elastic net, Single-nucleotide polymorphism, Environmental factors

\footnotetext{
* Correspondence: yanglei62@hznu.edu.cn

'Medical School, Hangzhou Normal University, 2318 Yuhangtang Rd, Hangzhou 310000, Zhejiang, China

Full list of author information is available at the end of the article
}

(c) The Author(s). 2020 Open Access This article is licensed under a Creative Commons Attribution 4.0 International License, which permits use, sharing, adaptation, distribution and reproduction in any medium or format, as long as you give appropriate credit to the original author(s) and the source, provide a link to the Creative Commons licence, and indicate if changes were made. The images or other third party material in this article are included in the article's Creative Commons licence, unless indicated otherwise in a credit line to the material. If material is not included in the article's Creative Commons licence and your intended use is not permitted by statutory regulation or exceeds the permitted use, you will need to obtain permission directly from the copyright holder. To view a copy of this licence, visit http://creativecommons.org/licenses/by/4.0/ The Creative Commons Public Domain Dedication waiver (http://creativecommons.org/publicdomain/zero/1.0/) applies to the data made available in this article, unless otherwise stated in a credit line to the data. 


\section{Background}

As a global public health issue causing significant morbidity and mortality, type 2 diabetes mellitus (T2DM) affects more than 380 million people worldwide [1, 2]. The International Diabetes Federation has estimated that the number of individuals with diabetes will increase from 240 million in 2007 to 642 million in 2040 [3, 4]. In China, because of scientific and technological advances as well as socioeconomic development, the number of patients with diabetes is predicted to increase from 20.8 million in 2000 to 42.3 million in 2030 [5, 6]. China has the largest number of people with diabetes, with 92.4 million adults currently affected [7, 8]. T2DM accounts for approximately $90 \%$ of all diabetes cases, with an overall prevalence of $9.1 \%$ of the population. T2DM occurs mainly when the body becomes unable to effectively use insulin and pancreatic $\beta$ cells to compensate for an enhanced insulin demand, leading to uncontrolled glucose homeostasis [2, 9]. Over time, poor glycemic control affects the blood vessels and nerves, accelerating the development and progression of neuropathies, micro- and macrovascular complications, and premature death $[9,10]$.

Most cases of T2DM are closely related to genetic and environmental risk factors [11, 12] and their interactions [13]. Previous genome-wide association studies [14-16] have identified numerous genetic polymorphisms and rare genetic variants associated with slight or significant effects on T2DM, suggesting that the disease results from complex interactions between genetic mechanisms and environmental factors. For instance, Zhang et al. [17] found a close relationship between the SLC12A3 gene and T2DM, and showed that a $\mathrm{T}$ allele in this gene had a modestly unfavorable impact on lipid levels. Ference et al. [18] showed that the genetic variants of the HMGCR gene are associated with T2DM. Ergen et al. [19] suggested ABCA1 polymorphism as a genetic marker of T2DM. Fumitaka et al. [20] identified the genetic susceptibility of patients with a novel common variant of rs964184 in ZPR1 to T2DM.

In addition to genetic predisposition, epidemiological risk factors play crucial roles in T2DM, such as gender differences, body mass index (BMI, weight in kilograms divided by height in square meters), lifestyle (e.g., smoking, alcohol consumption, etc.), and interactions between various factors [11-13, 21, 22].

We comprehensively analyzed the potential interactions between genes, physiological indices, biochemical indicators, and behavioral factors and T2DM. We constructed a model by elastic net that included genes and other environmental factors to identify variables strongly associated with T2DM rather than to predict the occurrence of T2DM.

\section{Methods}

\section{Subjects}

A total of 2323 subjects, who underwent physical examination at a community health service center from April 2013 to July 2013, were selected by cluster random sampling from 4 towns and townships in a district of Ningbo, Zhejiang Province. All subjects had to meet the following criteria: (1) Permanent residents aged more than 40 years old; (2) Han ethnic; (3) no consanguinity relation; (4) free from patients diagnosed with T2DM in April 2013, as well as patients with severe liver and kidney disease, malignant tumors and infectious diseases. We collected individual medical reports, lifestyle details, and blood samples and performed genotyping for singlenucleotide polymorphisms (SNPs) using the polymerase chain reaction-ligase detection reaction method. Interviews were performed in August 2016 to determine the subjects' incidence of T2DM. A total of 2113 people qualified for the study. T2DM was diagnosed based on World Health Organization guidelines [23]. The case group included 100 patients diagnosed with CAD between April 2013 and August 2016. The rest who did not develop type 2 diabetes in 2016 were in the control group. The study was approved by the Medical Ethics Committee of Hangzhou Normal University (No. 2013020), all participants signed informed consent forms. The study design is as follows (Fig. 1):

\section{Demographic information and epidemiological investigation}

Demographic variables mainly consisted of fundamental demographic criteria such as age, sex, education level and information on lifestyle such as smoking and drinking behavior. The main lifestyle variables were defined as follows. (1) Diet: "drink milk" and "drink soymilk" were defined as maintaining a certain amount of milk or soymilk intake every day, whereas "no milk intake habit" was defined as "not drinking". An average intake of fried food of less than 1 time per week was defined as "no fried food"; those who ate less than one sweet treat per week were defined as "not eating sweets". (2) Smoking: smoking behavior was defined as smoking at least one cigarette per day for at least 1 year. (3) Drinking: drinking behavior was defined as drinking white wine $\geq 50 \mathrm{~g}$, red wine $\geq 150 \mathrm{~g}$, or beer $\geq 500 \mathrm{~g}$ on average every day for 1 year or more. (4) Physical activity classification: "there is little physical activity, such as desk workers such as secretary" was defined as "sedentary"; "Light physical activity" was defined as "office work, repair of electrical clocks and watches, sales clerks, hotel services, chemical laboratory operations, lectures, etc."; “Students' daily activities, motor vehicle driving, electrical installation, lathe operation, metal cutting, etc." was defined as "moderate physical activities"; "Non-mechanized agricultural labor, 


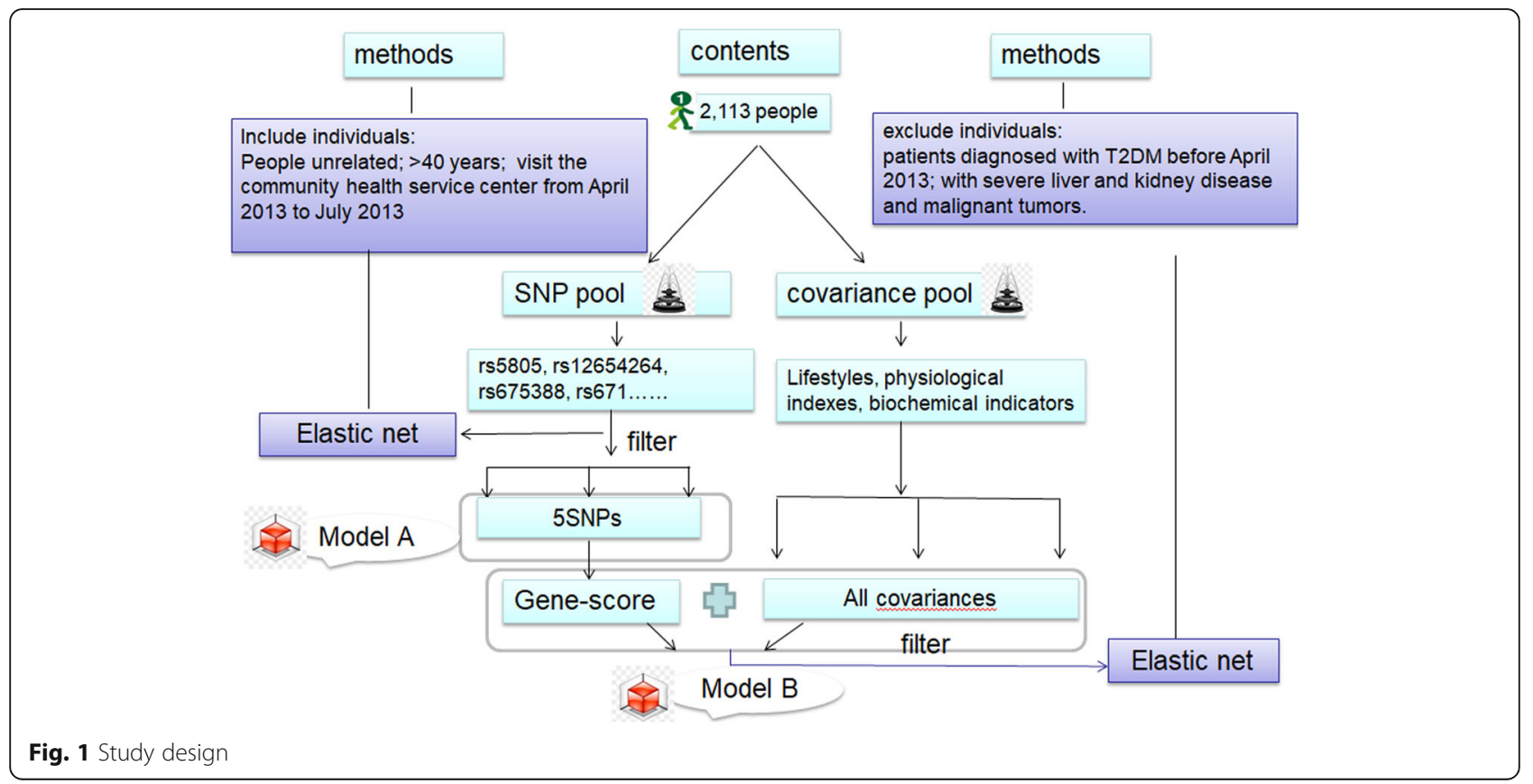

steelmaking, dancing, sports movement, loading and unloading, mining, loading and unloading cargo, construction workers, etc." was defined as "heavy physical activity".

Aaccording to standard protocols, anthropometric data, including weight, waist circumference, BMI, total cholesterol (TC), triglycerides (TG), high-density lipoproteincholesterol (HDL-C), and low-density lipoproteincholesterol (LDL-C) levels, systolic blood pressure (SBP), diastolic blood pressure (DBP) were evaluated by professional medical examinations.

Blood samples were collected from the antecubital vein after the subjects had fasted for $\geq 8 \mathrm{~h}$. Part of the collected samples was used to examine biochemical indicators such as serum lipid levels, whereas the other part was transferred into a test tube containing anticoagulant solution to extract DNA.

\section{Isolation of genomic DNA}

Genomic DNA was extracted from the blood cells using a standard phenol/chloroform extraction method, centrifuged, and stored at $-80^{\circ} \mathrm{C}$. All genomic DNA samples were analyzed by electrophoresis. DNA was extracted using Tiangen Blood Genomic DNA extraction kits (Tiangen Biotech, Beijing, China) and sent to Shanghai Jierui Biological Engineering Co., Ltd., for genotyping analysis using the polymerase chain reaction (PCR)-ligase detection reaction (LDR) method (Generay Biotech Company, Shanghai, China). For this part, we have covered this in detail in previous articles [24]. For quality control, we randomly chose $10 \%$ of samples for regenotyping, and the concordance was $100 \%$.

\section{SNP selection and genotyping}

Peripheral venous blood samples were collected from the study subjects to evaluate four physiological indicators of blood lipids (TC, TG, HDL-C, LDL-C and gene locus information. SNPs were mainly searched using the PubMed, Kyoto Encyclopedia of Genes and Genomes, and GeneCard databases. The specific screening process was as follows: (1) Literature related to gene polymorphisms, lipid levels, and atherosclerosis were searched in NCB-PubMed, and SNPs were screened; (2) GeneView information was obtained for relevant SNPs from the GeneCards database and NCBI database, and then, missense mutations, 3' untranslated region (3' UTR), 5' UTR, or transcription factor-binding sites were selected; (3) The minor allele frequency (MAF) of SNPs in the Chinese population was detected from the HapMap database for the international human genome, and SNP sites with MAF values greater than 0.05 were screened; (4) Haploview software was used to conduct linkage imbalance analysis on all selected sites, and tagSNP was selected with $r^{2} \geq 0.8$ as the standard.

This process identified 103 SNPs, including those in SLC12A3, HMGCR, ABCA1, and KCNJ1, among others. Information regarding all SNP loci is shown in Table S1.

\section{Statistical analysis}

Statistical analysis was conducted with SPSS 24.0 software (SPSS, Inc., Chicago, IL, USA) and RStudio (Version 1.1.456. RStudio: Integrated development environment for R. Boston, MA, USA; http://www.rstudio.org/) using the glmnet package [25]. Elastic net regularization was used for feature selection which automatically performs variable 
selection to shrink the model to reduce over-fitting and co-variate correlation [26]. This technique has been shown to be superior to other methods of analysis when the set of features is much larger than the number of cases [27]. Chi-squared test, $t$ test, Fisher exact test (for categorical variables), and Wilcoxon rank sum test (for continuous variables) were used to evaluate demographic characteristics and SNP genotypes. The odd ratios (ORs) and $95 \%$ confidence intervals (CIs) by logistic regression analysis were used to estimate the associations between variables (such as genetic models and lifestyles)and the risk of T2DM. The logistic-regression model based on 102 SNP feature selection and model based on SNP/ lifestyle features were separately developed on an elastic net. A gene-score was calculated for each person via the elastic net of 5 selected SNPs weighted by their respective coefficients. The gene-scores were combined with 31 environmental variables and 6 variables were screened out, including gene-scores with nonzero coefficients as determined by elastic net. Finally, receiver operating characteristic (ROC) curves were plotted to assess the efficiency of the model. Acoording to Knol [28], we used Excel software to identified interaction (RERI), OR, and 95\% CI. Haploview, plink, and g-plink were used to calculate the $p$ values of Hardy-Weinberg equilibrium. In all analyses, $p$ values $<0.05$ were considered to indicate a statistically significant difference. The purpose of this study was not to establish a model with good performance in predicting T2DM, but rather to explain T2DM through a relatively meaningful model, such as which SNP or environmental factors are likely to cause the disease.

\section{Results}

\section{General characteristics}

The subjects included 2163 randomly selected men and women: $54 \%$ of the subjects were female and $46 \%$ were male. A summary of their demographic characteristics such as age, sex, BMI, weight, HDL-C, LDC-C, TC, and TG is shown in Table 1. There were significant differences in age, weight, BMI, waistline, SBP, DBP, TG, LDL-C, degree of education, and exercise frequency between the case and control groups $(p<0.05)$ (Table 1). All studied SNPs in the control subjects were in Hardy-Weinberg equilibrium $(p>$ 0.05). The MAF of each SNP was more than $5 \%$ to ensure that this study had sufficient statistical power (Table S1).

\section{Gene-based model: SNPs associated with T2DM}

Elastic net penalization allows for variable selection by shrinking the coefficients of the variables not related to the response to zero. Thus, variables with non-zero

Table 1 Basic characteristics

\begin{tabular}{|c|c|c|c|c|}
\hline Characteristic & T2DM (+) & T2DM (-) & $t / z / x^{2}$ & $P$ \\
\hline Total & 100 & 2013 & & \\
\hline Age, Median (IQR), year & $64(14.5)$ & $62(17)$ & 7.04 & 0.0080 \\
\hline Sex, n (\%) & & & 1.23 & 0.2680 \\
\hline Male & $49(49)$ & $917(45.5)$ & & \\
\hline Female & $51(51)$ & 1096(54.5) & & \\
\hline Weight, Median (IQR), year & $63.2(5.05)$ & $59.4(12.82)$ & 5.49 & 0.0192 \\
\hline $\mathrm{BMI}$, mean $\pm \mathrm{SD}, \mathrm{kg} / \mathrm{m} 2$ & $24.06 \pm 4.55$ & $23.15 \pm 3.84$ & 8.32 & 0.0039 \\
\hline Waistline, Median (IQR), cm & $82.87(11)$ & & 15.10 & 0.0001 \\
\hline SBP, Median (IQR), mmHg & $145(16.5)$ & $136(30)$ & 23.80 & $<0.001$ \\
\hline DBP, Median (IQR), mmHg & $90(15)$ & $80(16)$ & 17.27 & $<0.001$ \\
\hline TC, Median (IQR), mmol/L & $4.99(1.39)$ & $4.85(1.27)$ & 1.99 & 0.1584 \\
\hline $\mathrm{TG}$, Median (IQR), mmol/L & $1.50(0.65)$ & $1.28(0.87)$ & 4.12 & 0.0423 \\
\hline $\mathrm{HDL}-\mathrm{C}$, Median (IQR), $\mathrm{mmol} / \mathrm{L}$ & $1.24(0.32)$ & $1.26(0.38)$ & 0.13 & 0.7179 \\
\hline LDL-C, Median (IQR), mmol/L & $3.18(1.37)$ & $2.98(1.11)$ & 5.11 & 0.0238 \\
\hline Degree of education, n (\%) & & & 7.23 & 0.0072 \\
\hline Primary school education & $78(3.6)$ & 1468(67.9) & & \\
\hline Junior middle school education & $14(0.6)$ & $520(24.0)$ & & \\
\hline High school and more than high school education & 1 & $82(3.8)$ & & \\
\hline Frequency of exercise, $\mathrm{n}(\%)$ & & & 17.22 & $<0.001$ \\
\hline$\geq 4$ times/week & 20(0.9) & 1708(79) & & \\
\hline$<4$ times/week & $73(3.4)$ & $362(16.7)$ & & \\
\hline
\end{tabular}

$I Q R$ interquartile range, $S D$ standard deviation, $B M I$ body mass index, $T C$ total cholesterol, $T G$ triglyceride, $H D L-C$ high-density lipoprotein cholesterol, $L D L-C$ lowdensity lipoprotein cholesterol, SBP systolic blood pressure, DBP diastolic blood pressure 
coefficients are considered as important predictors. Selection of the shrinkage parameter (lambda) for the elastic net model was performed by 20 repetitions of 10 -fold cross-validation. The one-standard-error rule was used. Using this value as the minimum lambda value resulted in 5 variables being included in the prognostic model.

Initially, $102 \mathrm{SNPs}$ were reduced to 5 potential predictors in 2163 people, and were features with nonzero coefficients in the elastic net model (Model A). The 5 potential SNPs were rs5805 in SLC12A3, rs12654264 in HMGCR, rs2065412 and rs414936 in ABCA1, and rs964184 in ZPR1. The area under the ROC curve for model A was 0.63 (Fig. 2). Figure 2 shows the ROC curves generated for each model. The black line represents model A, which was generated from SNP features using elastic net regression.

Table 2 is the association between the 5 SNPs and environmental factors with T2DM, which was examined under each gene model. Without adjustment, the recessive models of rs12654264 and dominant model of rs2065412 and rs4149336 were found to be significantly associated with T2DM (Table 2). In the additive models, the TT genotype of rs12654264 and CT genotype of rs4149336 were associated with a reduced risk of T2DM (unadjusted $\mathrm{OR}=0.45,95 \% \mathrm{CI}=0.24-0.84, p=0.012$; unadjusted $\mathrm{OR}=$ $0.59,95 \% \mathrm{CI}=0.37-0.92, p=0.019)$. Subjects carrying the TT genotype in the recessive model of rs12654264, CC + CT genotype in the dominant model of rs2065412, and TT + CT genotype in the dominant model of rs4149336 showed a lower risk of CAD than those with the AT+AA genotype, TT genotype, and CC genotype (unadjusted $\mathrm{OR}=0.53,95 \% \mathrm{CI}=0.32-0.90, p=0.019$; unadjusted $\mathrm{OR}=$
$0.30,95 \% \mathrm{CI}=0.11-0.81, p=0.018$; unadjusted $\mathrm{OR}=0.57$, $95 \% \mathrm{CI}=0.38-0.87, p=0.009)$.

\section{All covariance-based model}

Considering that model A only focused on the influence of genes on $\mathrm{CAD}$, we recreated model $\mathrm{B}$ that included genetic characteristics and physiological, biochemical, and lifestyle indicators to identify factors related to CAD. When 102 SNPs were reduced to 5 potential predictors, the features of the 5 SNPs were presented in the gene-score calculation formula by elastic net. A genescore was calculated for every person by linear combination of the selected features weighted by their respective coefficients. The gene-score was combined with 31 lifestyle variables, and 6 variables with gene-scores with nonzero coefficients were screened out by elastic net (Model B). The red line represents the model B generated from the gene-score and lifestyle features using the same technique. The area under the ROC for model B was 0.71 (Fig. 2). The 6 variables were gene-score, hypertension, meat intake, waistline, education degree, and exercise frequency (Table S2 and Table 3).

After adjusting for these 6 variables, the recessive models of rs12654264 and dominant models of rs2065412 and rs4149336 were still significantly associated with T2DM (adjusted $\mathrm{OR}=0.53,95 \% \mathrm{CI}=0.32-0.91, p=0.02$; adjusted $\mathrm{OR}=0.73,95 \% \mathrm{CI}=0.48-1.10, p=0.02$; adjusted $\mathrm{OR}=0.54,95 \% \mathrm{CI}=0.37-0.88, p=0.01)$ (Table 2). In the additive models, the AA genotype of rs12654264, TT genotype of rs2065412, and CC genotype of rs4149336 still increased the risk of T2DM (Table 2). Table S2 is the

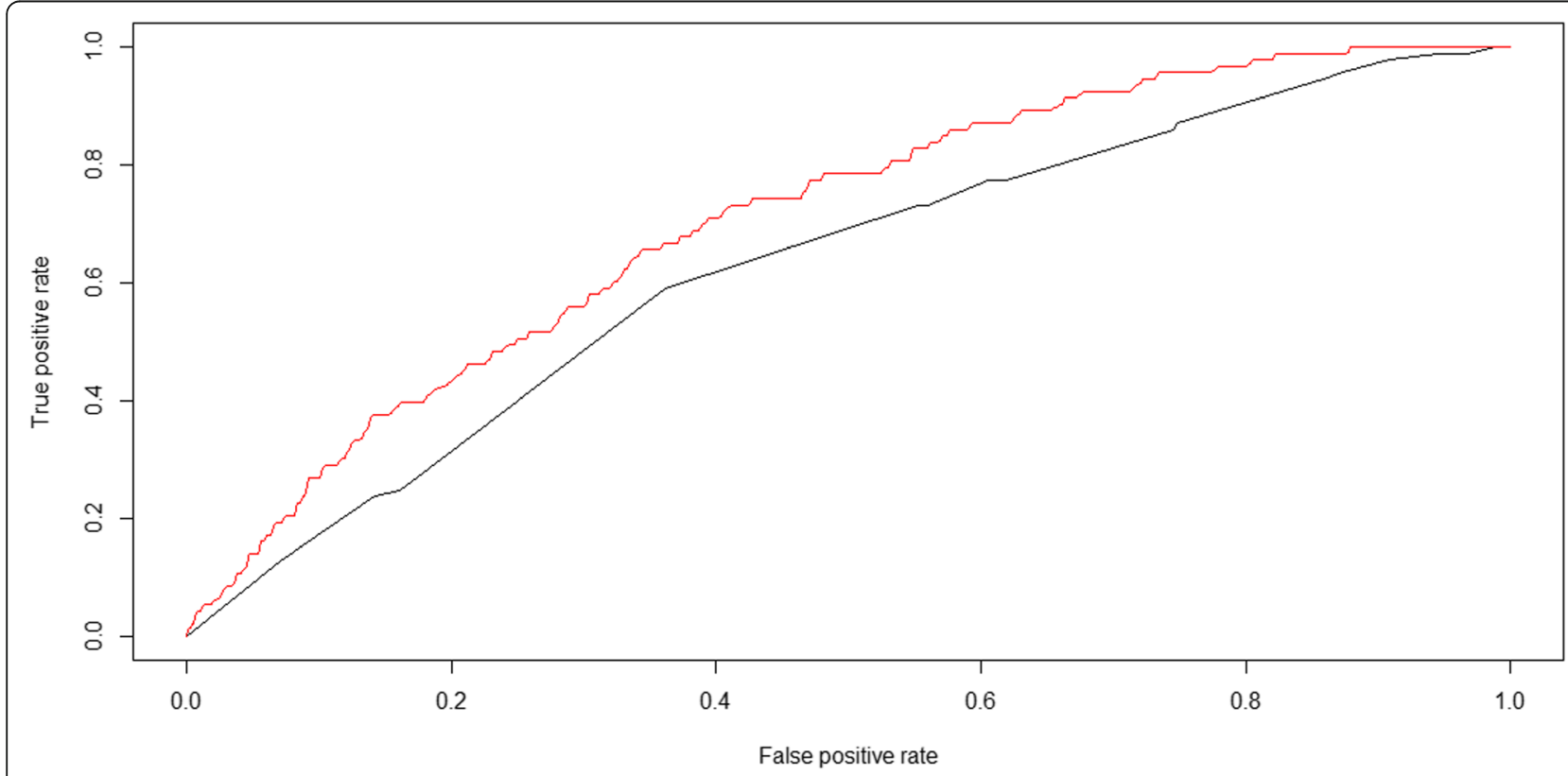

Fig. 2 ROC curves of model A and model B: The black line represents model A; The red line represents model B 
Table 2 Associations of genetic models with risk of type 2 diabetes mellitus

\begin{tabular}{|c|c|c|c|c|c|}
\hline SNP & Genotype & Unadjusted OR(95\%Cl) & Unadjusted P & Adjusted OR(95\%Cl) & Adjusted $\boldsymbol{P}$ \\
\hline \multicolumn{6}{|l|}{ Rs5805 } \\
\hline \multirow[t]{2}{*}{ Additive } & $\mathrm{CT} / \mathrm{TT}$ & $0.73(0.47 \sim 1.13)$ & 0.155 & $0.71(0.46 \sim 1.10)$ & 0.130 \\
\hline & $\mathrm{CC} / \mathrm{TT}$ & $0.34(0.10 \sim 1.09)$ & 0.069 & $0.34(0.11 \sim 1.12)$ & 0.077 \\
\hline Dominant & $\mathrm{CC}+\mathrm{CT} / \mathrm{TT}$ & $0.67(0.44 \sim 1.02)$ & 0.062 & $0.66(0.43 \sim 1.01)$ & 0.050 \\
\hline Recessive & $C C / C T+T T$ & $0.39(0.12 \sim 1.23)$ & 0.107 & $0.40(0.12 \sim 1.28)$ & 0.120 \\
\hline \multicolumn{6}{|l|}{ Rs12654264 } \\
\hline \multirow[t]{2}{*}{ Additive } & AT/AA & $0.79(0.48 \sim 1.30)$ & 0.347 & $0.81(0.49 \sim 1.35)$ & 0.414 \\
\hline & TT/AA & $0.45(0.24 \sim 0.84)$ & 0.012 & $0.46(0.25 \sim 0.87)$ & 0.017 \\
\hline Dominant & $\pi+\mathrm{AT} / \mathrm{AA}$ & $0.66(0.41 \sim 1.06)$ & 0.087 & $0.68(0.42 \sim 1.10)$ & 0.512 \\
\hline Recessive & TT/AT+AA & $0.53(0.32 \sim 0.90)$ & 0.019 & $0.53(0.32 \sim 0.91)$ & 0.021 \\
\hline \multicolumn{6}{|l|}{ Rs2065412 } \\
\hline \multirow[t]{2}{*}{ Additive } & $\mathrm{CT} / \mathrm{TT}$ & $0.31(0.11 \sim 0.84)$ & 0.022 & $0.31(0.11 \sim 0.86)$ & 0.299 \\
\hline & $\mathrm{CC} / \mathrm{TT}$ & - & 0.999 & - & 0.999 \\
\hline Dominant & $\mathrm{CC}+\mathrm{CT} / \mathrm{TT}$ & $0.30(0.11 \sim 0.81)$ & 0.018 & $0.73(0.48 \sim 1.10)$ & 0.020 \\
\hline Recessive & $\mathrm{CC} / \mathrm{CT}+\mathrm{TT}$ & - & 0.999 & - & 0.999 \\
\hline \multicolumn{6}{|l|}{ Rs4149336 } \\
\hline \multirow[t]{2}{*}{ Additive } & $\mathrm{CT} / \mathrm{CC}$ & $0.59(0.37 \sim 0.92)$ & 0.019 & $0.59(0.37 \sim 0.92)$ & 0.021 \\
\hline & TT/CC & $0.53(0.25 \sim 1.14)$ & 0.103 & $0.52(0.24 \sim 1.19)$ & 0.094 \\
\hline Dominant & $\pi+C T / C C$ & $0.57(0.38 \sim 0.87)$ & 0.009 & $0.57(0.37 \sim 0.88)$ & 0.010 \\
\hline Recessive & $T T / C T+C C$ & $0.68(0.32 \sim 1.41)$ & 0.300 & 0.66(0.31 1.39) & 0.271 \\
\hline \multicolumn{6}{|l|}{ Rs964184 } \\
\hline \multirow[t]{2}{*}{ Additive } & $\mathrm{CG} / \mathrm{CC}$ & $1.31(0.84 \sim 2.03)$ & 0.232 & $1.40(0.90 \sim 2.18)$ & 0.140 \\
\hline & $\mathrm{GG} / \mathrm{CC}$ & $2.24(0.99 \sim 5.09)$ & 0.055 & $2.38(1.03 \sim 5.53)$ & 0.043 \\
\hline Dominant & $\mathrm{GG}+\mathrm{CG} / \mathrm{CC}$ & $1.41(0.93 \sim 2.13)$ & 0.111 & $1.50(0.98 \sim 2.30)$ & 0.060 \\
\hline Recessive & $\mathrm{GG} / \mathrm{CG}+\mathrm{CC}$ & $2.21(0.91 \sim 4.52)$ & 0.085 & $2.10(0.93 \sim 4.79)$ & 0.076 \\
\hline
\end{tabular}

Adjusted for waist circumference, the history of hypertension, the intake of meat, degree of education, exercise. The meaning of "l" is "VS"; the meaning of " + " is "and"

Elastic net regularisation feature selection for gene-score and lifestyles.

\section{Interactions between gene polymorphism and other covariance estimators for the risk of T2DM}

Considering that interactions may occur between variables in the model, we further explored these interactions

Table 3 Associations of gene-score and lifestyles with risk of type 2 diabetes mellitus

\begin{tabular}{llll}
\hline Characters & OR & $95 \% \mathrm{Cl}$ & $\boldsymbol{P}$ \\
\hline Gene-score & 36.51 & $6.24-213.60$ & $<\mathbf{0 . 0 0 1}$ \\
The history of hypertension & 3.31 & $2.01-5.48$ & $<\mathbf{0 . 0 0 1}$ \\
The intake of meat & 1.50 & $0.98-2.31$ & 0.06 \\
Waist circumference & 1.05 & $1.02-1.07$ & $<\mathbf{0 . 0 0 1}$ \\
Degree of education & 0.50 & $0.30-0.83$ & $\mathbf{0 . 0 0 7}$ \\
Exercise & 0.80 & $0.66-0.98$ & $\mathbf{0 . 0 3 2}$ \\
\hline
\end{tabular}

The intake of meat, classified into never eat white meat,1-4 times every week, 5-7 times every week; $>7$ times every week; $p$ value $<0.05$ was considered statistically significant through an extensive literature survey. At the same time, we had studied the correlation between the kinds of factors, for example, compared to individuals with lower genetic risk and healthy lifestyle, whether individuals with similar lifestyle but higher genetic risk have a higher starting risk of developing disease. Table 4 shows the effects of the interaction between 5 SNPs and hypertension on T2DM. In rs5805, rs12654264, rs4149336, and rs964184, compared to subjects without a history of hypertension carrying the non-risk genotype, those with a history of hypertension who carried the non-risk or risk allele were at a higher risk of T2DM $(\mathrm{OR}=2.95,95 \% \mathrm{CI}=1.38-6.30$, $p=0.005 ; \mathrm{OR}=4.59,95 \% \mathrm{CI}=2.22-9.49, p<0.001 ; \mathrm{OR}=$ 15.39, $95 \% \mathrm{CI}=2.04-116.30, \quad p=0.008 ; \quad \mathrm{OR}=22.83$, $95 \% \mathrm{CI}=3.15-165.69, p=0.002)$. Although an interaction between the 5 SNPs and hypertension was not found ( $p$ values of RERI >0.05), there was a cumulative effect in each model. For example, in rs5805, within the strata of $\mathrm{TT}$, people with a history of hypertension had a higher risk of T2DM than those without a history of 
$\begin{array}{ll}\text { Li et al. BMC Public Health } & \text { (2020) 20:1024 }\end{array}$

Page 7 of 12

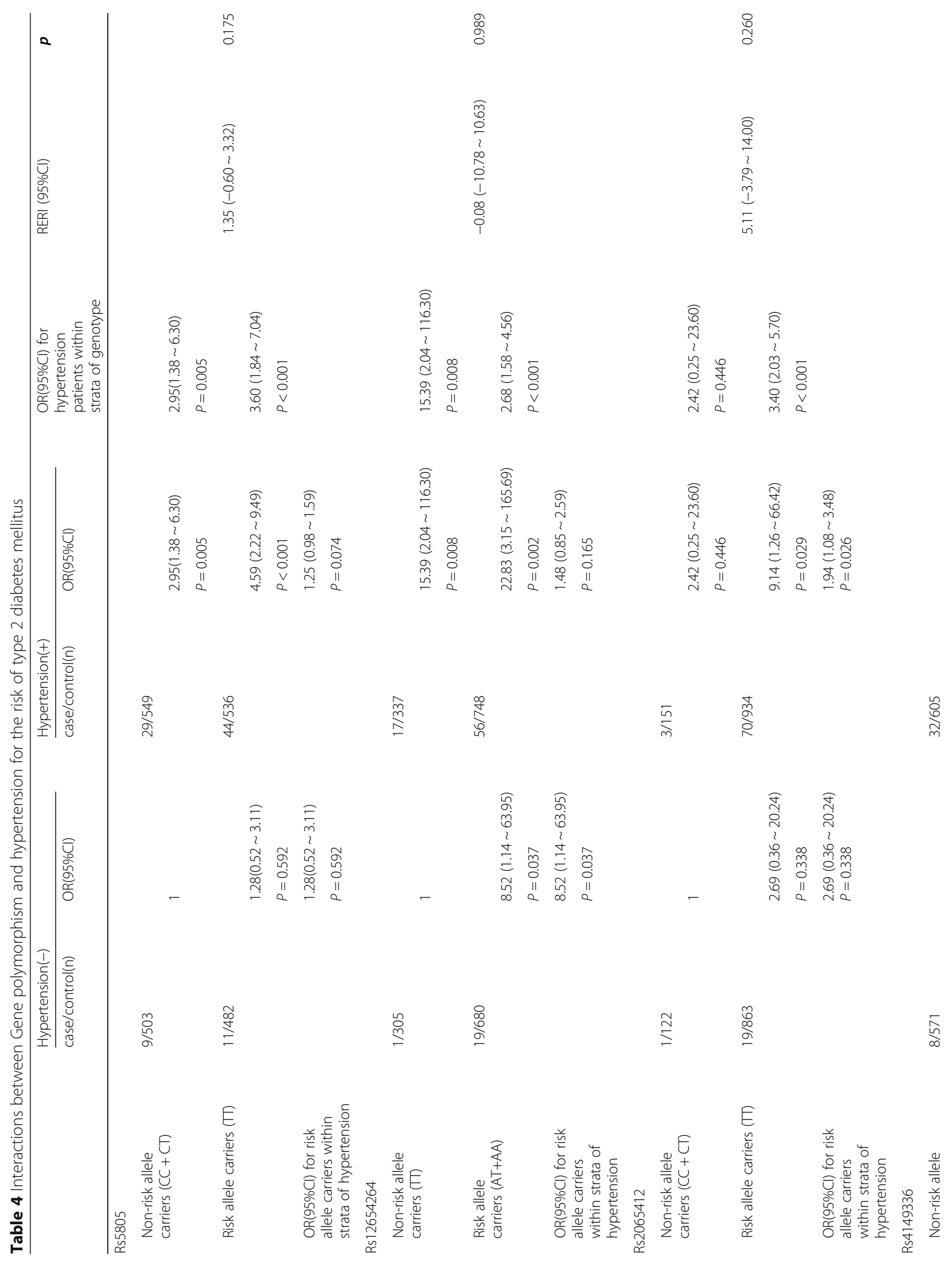


Li et al. BMC Public Health $\quad$ (2020) 20:1024

Page 8 of 12

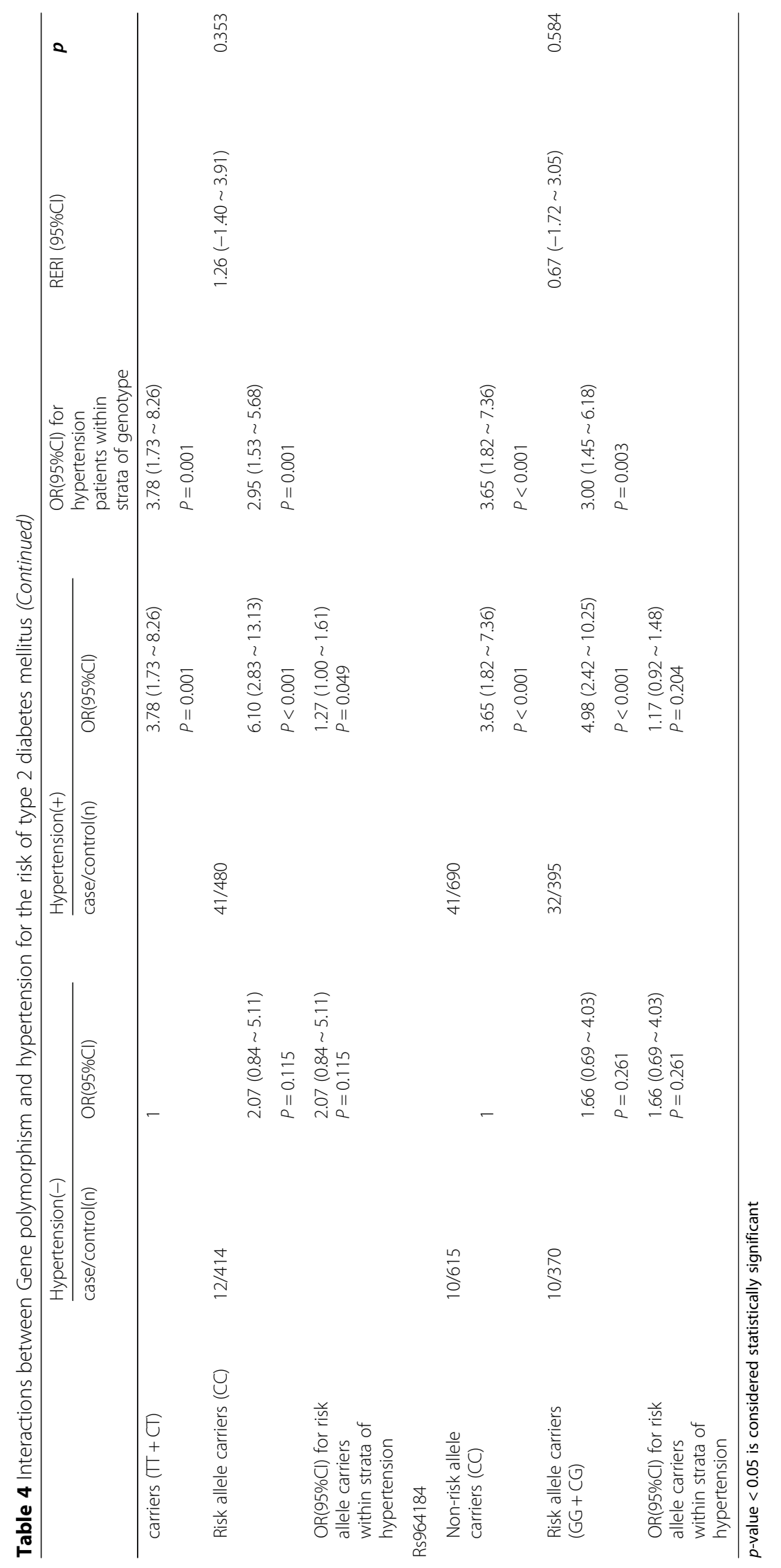


hypertension $(\mathrm{OR}=3.60,95 \% \mathrm{CI}=1.84-7.04, p<0.001)$; in rs12654264, within the strata of AT+AA, compared to in people without a history of hypertension, those with a history of hypertension were at a higher risk of T2DM (OR = 2.68, $95 \% \mathrm{CI}=1.58-4.56, p<0.001$ ); in rs2065412, within the strata of hypertension, subjects carrying TT genotype had a higher risk of T2DM than those carrying the CC + CT genotype $(\mathrm{OR}=1.94,95 \% \mathrm{CI}=1.08-3.48, p=0.026)$; in rs4149336, within the strata of hypertension, subjects carrying the CC genotype had a higher risk of T2DM than those carrying TT + CT; within the strata of the CC genotype, people with a history of hypertension were at a higher risk of $\mathrm{T} 2 \mathrm{DM}(\mathrm{OR}=1.27,95 \% \mathrm{CI}=1.00-1.61, p=$ 0.049; $\mathrm{OR}=2.95,95 \% \mathrm{CI}=1.53-5.68, p=0.001$ ) (Table 4).

Table 5 shows the effect of the interaction between meat intake, exercise frequency, dyslipidemia, and hypertension on T2DM. For meat intake, compared to in people without hypertension who eat white meat less than three times per week, those with hypertension who eat meat were at a higher risk of T2DM regardless of the

Table 5 Interactions between other lifestyles and hypertension for the risk of type 2 diabetes mellitus

\begin{tabular}{|c|c|c|c|c|c|c|c|}
\hline & \multicolumn{2}{|l|}{ Hypertension(-) } & \multicolumn{2}{|l|}{ Hypertension(+) } & \multirow{2}{*}{$\begin{array}{l}\text { OR }(95 \% \mathrm{Cl}) \text { for } \\
\text { hypertension } \\
\text { patients within } \\
\text { strata of other } \\
\text { lifestyles }\end{array}$} & \multirow[t]{2}{*}{ RERI $(95 \% \mathrm{Cl})$} & \multirow[t]{2}{*}{$p$} \\
\hline & case/control(n) & $\mathrm{OR}(95 \% \mathrm{Cl})$ & case/control(n) & $\mathrm{OR}(95 \% \mathrm{Cl})$ & & & \\
\hline \multicolumn{8}{|l|}{ The intake of meat } \\
\hline \multirow[t]{3}{*}{$<3$ times/week } & $10 / 682$ & & $46 / 756$ & & & & \\
\hline & & 1 & & $4.15(2.08 \sim 8.29)$ & $4.15(2.08 \sim 8.29)$ & & \\
\hline & & & & $P<0.001$ & $P<0.001$ & & \\
\hline \multirow[t]{3}{*}{$\geq 3$ times/week } & $10 / 303$ & & $27 / 329$ & & & $0.20(-2.74 \sim 3.13)$ & 0.896 \\
\hline & & $2.25(0.93 \sim 5.46)$ & & $5.60(2.68 \sim 11.7)$ & $1.35(0.82 \sim 2.21)$ & & \\
\hline & & $P=0.073$ & & $P<0.001$ & $P=0.234$ & & \\
\hline \multirow{2}{*}{$\begin{array}{l}\text { OR }(95 \% \mathrm{Cl}) \text { for } \\
\text { people who eat } \\
\text { much more meat } \\
\text { within strata of } \\
\text { hypertension }\end{array}$} & & $2.25(0.93 \sim 5.46)$ & & $2.49(1.18 \sim 5.22)$ & & & \\
\hline & & $P=0.073$ & & $P=0.016$ & & & \\
\hline \multicolumn{8}{|c|}{ The frequency of exercise } \\
\hline \multirow[t]{3}{*}{$\geq 4$ times/week } & $3 / 489$ & & $24 / 319$ & & & & \\
\hline & & 1 & & $5.16(1.51 \sim 17.67)$ & $5.16(1.51 \sim 17.67)$ & & \\
\hline & & & & $P=0.009$ & $P=0.009$ & & \\
\hline \multirow[t]{3}{*}{$<4$ times/week } & $17 / 496$ & & $49 / 766$ & & & $48.38(-11.90 \sim 108.66)$ & 0.116 \\
\hline & & $26.98(7.82 \sim 93.07)$ & & $79.55(24.64 \sim 256.97)$ & $2.95(1.65 \sim 5.27)$ & & \\
\hline & & $P<0.001$ & & $P<0.001$ & $P<0.001$ & & \\
\hline \multirow{2}{*}{$\begin{array}{l}\text { OR }(95 \% \mathrm{Cl}) \text { for } \\
\text { people who eat } \\
\text { much more meat } \\
\text { within strata of } \\
\text { hypertension }\end{array}$} & & $26.98(7.82 \sim 93.07)$ & & $15.42(8.77 \sim 27.12)$ & & & \\
\hline & & $P<0.001$ & & $P<0.001$ & & & \\
\hline \multicolumn{8}{|l|}{ Dyslipidemia } \\
\hline \multirow[t]{3}{*}{ Dyslipidemia (-) } & $3 / 489$ & & $24 / 319$ & & & & \\
\hline & & 1 & & $12.26(3.66 \sim 41.06)$ & $12.26(3.66 \sim 41.06)$ & & \\
\hline & & & & $P<0.001$ & $P<0.001$ & & \\
\hline \multirow[t]{3}{*}{ Dyslipidemia (+) } & $17 / 496$ & & $49 / 766$ & & & $-6.43(-17.08 \sim 4.22)$ & 0.237 \\
\hline & & $5.59(1.63 \sim 19.19)$ & & $10.43(3.23 \sim 33.64)$ & $1.87(1.06 \sim 3.28)$ & & \\
\hline & & $P=0.006$ & & $P<0.001$ & $P=0.03$ & & \\
\hline \multirow{2}{*}{$\begin{array}{l}\text { OR }(95 \% \mathrm{Cl}) \text { for } \\
\text { dyslipidemia } \\
\text { patients within } \\
\text { strata of } \\
\text { hypertension }\end{array}$} & & $5.59(1.63 \sim 19.19)$ & & $0.85(0.51 \sim 1.41)$ & & & \\
\hline & & $P=0.006$ & & $P=0.529$ & & & \\
\hline
\end{tabular}


number of times per week $(\mathrm{OR}=4.15,95 \% \mathrm{CI}=2.08-$ $8.29, p<0.001 ; \mathrm{OR}=5.60,95 \% \mathrm{CI}=2.68-11.7, p<0.001)$. Within the strata of hypertension, people who eat white meat more than three times per week had a higher risk of T2DM than people who eat white meat less than three times per week $(\mathrm{OR}=2.49,95 \% \mathrm{CI}=1.18-5.22, p=$ 0.016). For the frequency of exercise, compared to in those without hypertension who had a good exercise habit ( $\geq 4$ times/week), those with hypertension who did more or less exercises were at a higher risk of T2DM $(\mathrm{OR}=5.16,95 \% \mathrm{CI}=1.51-17.67, p=0.009 ; \mathrm{OR}=79.55$, $95 \% \mathrm{CI}=24.64-256.97, p<0.001)$. Within the strata of hypertension, people who exercised less than 3 times per week had a higher risk of T2DM than those who exercised less than 4 times per week; additionally, within the strata of those who exercised less than 4 times per week, people with hypertension had a higher risk of T2DM than people without hypertension $(\mathrm{OR}=15.42,95 \% \mathrm{CI}=$ 8.77-27.12, $p<0.001 ; \mathrm{OR}=2.95,95 \% \mathrm{CI}=1.65-5.27, p<$ 0.001). Compared to subjects without dyslipidemia or hypertension, those who had dyslipidemia only, hypertension only, or two diseases at the same time were at a higher risk of $\mathrm{T} 2 \mathrm{DM}(\mathrm{OR}=12.26,95 \% \mathrm{CI}=3.66-41.06$, $p<0.001 ; \quad \mathrm{OR}=5.59, \quad 95 \% \mathrm{CI}=1.63-19.19, \quad p=0.006$; $\mathrm{OR}=10.43,95 \% \mathrm{CI}=3.23-33.64, p<0.001)$. Interactions between the 3 models were not detected ( $p$ values of RERI > 0.05) (Table 5).

\section{Discussion}

To construct the model, 133 candidate features were reduced to 7 potential predictors by examining the predictor-outcome association by shrinking the regression coefficients using the elastic net method. This method not only is superior to the method of choosing predictors based on the strength of their univariable association with outcome [27-29], but also enables the panel of selected features to be combined into a model. Thus, the model, which makes use of easily accessible metrics, can serve as a more convenient biomarker for explaining T2DM.

As T2DM is a complex disorder, and several genes have been implicated in its etiology and evolution. The identification of risk alleles is useful because if the involved genes and their functions are known, this information can be used to develop prevention, treatment, prognosis prediction, and/or curative methods for the disease. In the gene-based model, we examined the influence of genetic polymorphisms in four genes (SLC12A3, HMGCR, ABCA1, ZPR1) on T2DM through elastic net screening. Our data demonstrated that rs5805 in SLC12A3, rs12654264 in HMGCR, rs2065412 and rs414936 in ABCA1, and rs96418 in ZPR1 were significantly associated with T2DM.
We found that the minor allele ("C") of rs5805 in SLC12A3 was associated with a reduced risk of T2DM in the Chinese population. SLC12A3, located on 16q13, encodes a thiazide-sensitive $\mathrm{Na}+\mathrm{Cl}-$ cotransporter that mediates reabsorption of $\mathrm{Na}+$ and $\mathrm{Cl}-$ in the renal distal convoluted tubule and is expressed specifically in the kidneys [30]. Studies of SLC12A3 suggested that its genetic variants and rare mutations impact the development of hypertension and T2DM and/or nephropathy in Asian populations [31-33], which is consistent with the results of our study.

Our finding that variants in HMGCR were associated with the risk of diabetes. People carrying the TT genotype of rs12654264 are at a reduced risk of T2DM. Past studies have shown that, HMGCR variants are associated with obesity or its subphenotypes, such as weight, BMI, or waist circumference [34-36]. Thus, the mechanism by which HMGCR variants increase the risk of diabetes is likely mediated by weight gain.

ABCA1 plays an important role in cholesterol metabolism, particularly for HDL-C [37]. Previous investigations have showed that the ABCA1 gene may influence cardiovascular risk in the general population [38]. In addition, the ABCA1 R230C polymorphism may play an important role in maintaining glucose-mediated insulin secretion, in turn, leads to a 4-fold increase occurrence of diabetes [39]. Few studies have examined the role of ABCA1 polymorphism (rs2065412 and rs414936) in diabetes. We found a significantly higher frequency of both the $\mathrm{T}$ allele and genotype in the control group compared to in patients, indicating that the $\mathrm{T}$ allele is a protective factor against diabetes mellitus.

ZPR1 is located $\sim 1.6 \mathrm{~kb}$ upstream of the APOA5-A4C3-A1 gene complex. We found that rs964184 of ZPR1 was significantly associated with T2DM in Chinese individuals. This is consistent with the results of a previous study [40, 41]. rs964184 is in the intron region of ZPR1 at chromosome 11q23.3. ZPR1 is an essential regulatory protein for cell proliferation and signal transduction and may have multiple physiological functions [41, 42].

Multiple environmental risk factors, including gender, personal fitness status, weight, other physical conditions, and their interactions, can modulate serum lipid profiles, in addition to the effects of genetic background [13, 43, 44]. In the present study, demographic characteristics and lifestyle factors of the participants, including waistline, education degree, exercise frequency, hypertension, and meat intake, influenced T2DM. This has been confirmed in previous studies [11-13, 43, 44].

Epidemiological experts have suggested that quantitative interactions in the additive model are best suited for assessing the importance of interactions [26]. RERI, as well as the $p$ values and 95\%CI of RERI, were determined in this study. The RERI caused by an interaction 
is generally considered as the standard measure of an additive model interaction in case-control studies. We explored the interactions of gene-lifestyle factors, genebiochemical indicators, and certain lifestyle factors with the risk of T2DM. Although the interactions between these indices were not statistically significant, those carrying risk alleles of these SNPs who also had a history of hypertension or dyslipidemia were also at a high risk of disease.

This study had some limitations. First, our model was designed to explain the relationship between variables and disease and not to predict the risk of T2DM, and thus the model was not tested in new populations. Second, most responses related to lifestyles were obtained through questioning of the patients, and thus, there may have been recall bias. Finally, the conclusions may only be applicable to people in southern China. Studies in multiple regions and different populations using a randomized, large-scale, long-term design are needed.

\section{Conclusions}

In conclusion, the model which we built showed that four SNPs and 5 variance-covariance estimators were associated with T2DM in people in southern China. These results will provide a theoretical basis for gene and risk factor screening to prevent T2DM.

\section{Supplementary information}

Supplementary information accompanies this paper at https://doi.org/10. 1186/s12889-020-09130-5.

Additional file 1. The following are available online at www.mdpi.com/ $x x x / s 1$, Table S1. The information of 107 SNPs. Table S2. Elastic net regularisation feature selection for gene-score and lifestyles.

\section{Abbreviations \\ BCMO1: Beta-carotene monooxygenase 1; LDLR: Low-density lipoproteins receptor; PCSK9: Proprotein convertase subtilisin kexin type 9; \\ SLC12A3: Solute carrier family 12 member 3; KCNJ1: Potassium voltage-gated channel subfamily I member 1; CAD: Coronary artery disease; GWAS: Genome-wide association studies; SNPs: Single-nucleotide polymorphisms; AIDS: Acquired immune deficiency syndrome; TC: Total cholesterol; BMI: Body mass index; HDL-C: High-density lipoprotein cholesterol; LDL-C: Low-density lipoprotein cholesterol; MAF: Minor allele frequency}

\section{Acknowledgements}

We have consent to use authors' full names.

\section{Authors' contributions}

We thank all the individuals who participated in the present study. Z.L. and L.Y. had the original idea for the study, with all co-authors carried out the design. Z.L. drafted the manuscript, which was revised by all authors. Z.L. and T.-Y.Z. were responsible for recruitment and follow-up of study participants. C.-Y.Y. provided advanced statistical methods. All authors read and approved the final manuscript.

\section{Funding}

Funding for this study was provided through a grant by the Program for Zhejiang Leading Team of Science and Technology Innovation (no. 2011R50021).

\section{Availability of data and materials}

The datasets analysed during the current study are not publicly available due [the data is being further analyzed] but are available from the corresponding author L.Y. on reasonable request.

\section{Ethics approval and consent to participate}

All participants signed informed consent forms and the study was approved by the Medical Ethics Committee of Hangzhou Normal University (No. 2013020).

\section{Consent for publication}

Not applicable.

\section{Competing interests}

The authors declare that they have no competing interests.

\section{Author details}

${ }^{1}$ Medical School, Hangzhou Normal University, 2318 Yuhangtang Rd, Hangzhou 310000, Zhejiang, China. ${ }^{2}$ Medical School, Shihezi University, Shihezi 832000, China.

Received: 6 February 2020 Accepted: 16 June 2020

Published online: 29 June 2020

References

1. Yang W, Lu J, Weng J, Jia W, Ji L, Xiao J, et al. Prevalence of diabetes among men and women in China. N Engl J Med. 2010;362(12):1090-101. https://doi.org/10.1056/NEJMoa0908292.

2. International Diabetes Federation. International Diabetes Federation. 7th. IDF diabetes atlas; 2015. p. 1-144. http://www.diabetesatlas.org.

3. Shaw JE, Sicree RA, Zimmet PZ. Global estimates of the prevalence of diabetes for 2010 and 2030. Diabetes Res Clin Pract. 2010;87(1):4-14. https:// doi.org/10.1016/j.diabres.2009.10.007.

4. Martin-Timon I, Sevillano-Collantes C, Segura-Galindo A, Del Canizo-Gomez FJ. Type 2 diabetes and cardiovascular disease: have allriskfactorsthesame strength? World J Diabetes. 2014;5(4):444-70. https://doi.org/10.4239/wjd.v5. i4.444.

5. Boutayeb A, Boutayeb S. The burden of non-communicable diseases in developing countries. Int J Equity Health. 2005;4(1):2. https://doi.org/10. 1186/1475-9276-4-2

6. Guariguata L, Whiting DR, Hambleton I, Beagley J, Linnenkamp U, Shaw JE. Global estimates of diabetes prevalence for 2013 and projections for 2035 Diabetes Res Clin Pract. 2014;103(2):137-49. https://doi.org/10.1016/j.diabres. 2013.11.002

7. Yang LL, Shao J, Bian YY, Wu HQ, Shi LL, Zeng L, et al. Prevalence of type 2 diabetes mellitus among inland residents in China (2000-2014): a metaanalysis. J Diabetes Investig. 2016;7(6):845-52. https://doi.org/10.1111/jdi. 12514.

8. Cho NH, Shaw JE, Karuranga S, Huang Y, da Rocha Fernandes JD, Ohlrogge AW, et al. IDF diabetes atlas: global estimates of diabetes prevalence for 2017 and projections for 2045. Diabetes Res Clin Pract. 2018;138:271-81. https://doi.org/10.1016/j.diabres.2018.02.023.

9. WHO Global report on diabetes. http://www.who.int/diabetes/global-report/ en/.Accessed 9 May 2016.

10. Nery C, Moraes SRA, Novaes KA, Bezerra MA, Silveira PVC, Lemos A. Effectiveness of resistance exercise compared to aerobic exercise without insulin therapy in patients with type 2 dabetes mellitus: a meta-analysis. Braz J Phys Ther. 2017;21:400-15. https://doi.org/10.1016/j.bjpt.2017.06.004

11. American Diabetes Association. Standards of medical care in diabetes - 2013. Diabetes Care. 2013;36(supplement 1):11-66

12. Gulcher J, Stefansson K. Clinical risk factors, DNA variants, and the development of type 2 diabetes. N Engl J Med. 2009;359:2220-32 PMID 19020324.

13. Hu FB. Globalization of diabetes: the role of diet, lifestyle, and genes. Diabetes Care. 2011;34(6):1249-57. https://doi.org/10.2337/dc11-0442.

14. Zhou K, Donnelly L, Yang J, Li M, Deshmukh H, Van ZN, et al. Heritability of variation in glycaemic response to metformin: a genome-wide complex trait analysis. Lancet Diabetes Endocrinol. 2014;2(6):481-7. https://doi.org/10. 1016/S2213-8587(14)70050-6.

15. Jablonski KA, McAteer JB, de Bakker PI, Franks PW, Pollin TI, Hanson RL, et al. Commen variants in 40 genes assessed for diabetes incidence and response 
to metformin and lifestyle intervention in the diabetes prevention program. Diabetes. 2010;59(10):2672-81. https://doi.org/10.2337/db10-0543.

16. Andersen MK, Pedersen CE, Moltke I, Hansen T, Albrechtsen A, Grarup N. Genetics of type 2 diabetes: the power of isolated. Curr Diab Rep. 2016; 16(7):65. https://doi.org/10.1007/s11892-016-0757-Z.

17. Zhang R, Zhuang L, Li M, Zhang J, Zhao W, Ge X, et al. Arg913Gln of SLC12A3 gene promotes development and progression of end-stage renal disease in Chinese type 2 diabetes mellitus. Mol Cell Biochem. 2018;437(12):203-10. https://doi.org/10.1007/s11010-017-3120-z.

18. Ference BA, Robinson JG, Brook RD, Catapano AL, Chapman MJ, Neff DR, et al. Variation in PCSK9 and HMGCR and risk of cardiovascular disease and diabetes. N Engl J Med. 2016;375(22):2144-53. https://doi.org/10.1056/ NEJMoa1604304.

19. Ergen HA, Zeybek U, Gök O, Karaali ZE. Investıgatıon of ABCA1 C69T polymorphism in patients with type 2 diabetes mellitus. Biochem Med. 2012;22(1):114-20. https://doi.org/10.11613/bm.2012.013.

20. Tokoro F, Matsuoka R, Abe S, Arai M, Noda T, Watanabe S, et al. Association of a genetic variant of the ZPR1 zinc finger gene with type 2 diabetes mellitus. Biomed Rep. 2015;3(1):88-92. https://doi.org/10.3892/br.2014.379.

21. Wändell PE, Carlsson AC. Gender differences and time trends in incidence and prevalence of type 2 diabetes in Sweden-a model explaining the diabetes epidemic worldwide today? Diabetes Res Clin Pract. 2014;106(3): 90-2. https://doi.org/10.1016/j.diabres.2014.09.013.

22. Tobias M. Global control of diabetes: information for action. Lancet. 2011; 378(9785):3-4. https://doi.org/10.1016/50140-6736(11)60604-1.

23. World Health Organization. Definition, diagnosis and classification of diabetes mellitus and its complications. Report of A WHO consultation. Geneva: World Health Organization; 1999.

24. Zhao TY, Lei S, Huang L, Wang YN, Wang XN, Zhou PP, et al. Associations of Genetic Variations in ABCA1 and Lifestyle Factors with Coronary Artery Disease in a Southern Chinese Population with Dyslipidemia: A Nested Case-Control Study. Int J Environ Res Public Health. 2019;16(786). https://doi. org/10.3390/ijerph16050786.

25. Friedman J, Hastie T, Tibshirani R. Regularization paths for generalized linear models via coordinate descent. J Stat Softw. 2010;33(1):1-22 PMCID: PMC2 929880.

26. Deist TM, Dankers FJWM, Valdes G, Wijsman R, Hsu IC, Oberije C, et al. Machine learning algorithms for outcome prediction in (chemo) radiotherapy: an empirical comparison of classifiers. Med Phys. 2018;45(7): 3449-359. https://doi.org/10.1002/mp.12967.

27. Huang S, Hu C, Bell ML, et al. Regularized continuous-time Markov model via elastic net. Biometrics. 2018;74(3):1045. https://doi.org/10.1111/biom. 12868.

28. Knol MJ, VanderWeele TJ. Recommendations for presenting analyses of effect modification and interaction. Int J Epidemiol. 2012;41(2):514-20. https://doi.org/10.1093/ije/dyr218

29. Yu SC, Qi X, Hu YH, Zheng WJ, Wang QQ, Yao HY. Zhonghua Yu Fang Yi Xue Za Zhi. 2019;53(3):334-6. https://doi.org/10.3760/cma.j.issn.0253-9624. 2019.03.020

30. Bodhini D, Chidambaram M, Liju S, Revathi B, Laasya D, Sathish N, et al. Association of rs11643718 SLC12A3 and rs741301 ELMO1 variants with diabetic nephropathy in south Indian population. Ann Hum Genet. 2016;80: 336-41. https://doi.org/10.1111/ahg.12174

31. Ramachandran V, Ismail P, Stanslas J, Shamsudin N. Analysis of reninangiotensin aldosterone system gene polymorphisms in Malaysian essential hypertensive and type 2 diabetic subjects. Cardiovasc Diabetol. 2009;8:11. https://doi.org/10.1186/1475-2840-8-11.

32. Tanaka N, Babazono T, Saito S, Sekine A, Tsunoda T, Haneda M, et al. Association of solute carrier family 12 (sodium/chloride) member 3 with diabetic nephropathy, identified by genome-wide analyses of single nucleotide polymorphisms. Diabetes. 2003:52(11):2848-53. https://doi.org/ 10.2337/diabetes.52.11.2848.

33. Rajapurkar MM, John GT, Kirpalani AL, Abraham G, Agarwal SK, Almeida AF, et al. What do we know about chronic kidney disease in India: first report of the Indian CKD registry. BMC Nephrol. 2012;13:10. https://doi.org/10.1186/ 1471-2369-13-10.

34. Swerdlow DI, Preiss D, Kuchenbaecker KB, Holmes MV, Engmann JE, Shah T, et al. HMG-coenzyme a reductase inhibition, type 2 diabetes, and bodyweight: evidence from genetic analysis and randomised trials. Lancet 2015. 2015;385(9965):351-61. https://doi.org/10.1016/S0140-6736(14)61183-1.
35. The Cholesterol Treatment Trialists' (CTT) Collaboration. Efficacy of cholesterol-lowering therapy in 18,686 people with diabetes in 14 randomised trials of statins: a meta-analysis. Lancet. 2008;371(9607):117-25. https://doi.org/10.1016/S0140-6736(08)60104-X.

36. Besseling J, Kastelein JJ, Defesche JC, Hutten BA, Hovingh GK. Association between familial hypercholesterolemia and prevalence of type 2 diabetes mellitus. JAMA. 2015;313(10):1029-36. https://doi.org/10.1001/jama.2015. 1206.

37. Porchay I, Pean F, Belili N, Royer B, Cogneau J, Chesnier MC, et al. ABCA1 single nucleotide polymorphisms on high-density lipoprotein cholesterol and overweight: the D.E.S.I.R. study. Obesity. 2006;14(11):1874-49. https:// doi.org/10.1038/oby.2006.217.

38. García-Chapa EG, Leal-Ugarte E, Peralta-Leal V, Durán-González J, MezaEspinoza JP. Genetic epidemiology of type 2 diabetes in Mexican mestizos. Biomed Res Int. 2017;3937893. https://doi.org/10.1155/2017/3937893.

39. Villarreal-Molina MT, Aguilar-Salinas CA, Rodríguez-Cruz M, Riaño D, Villalobos-Comparan M, Coral-Vazquez R, et al. The ATP-binding cassette transporter A1 R230C variant affects HDL cholesterol levels and BMI in the Mexican population: association with obesity and obesity-related comorbidities. Diabetes. 2007;56(7):1881-7. https://doi.org/10.2337/db060905.

40. Kooner JS, Saleheen D, Sim X, Sehmi J, Zhang W, Frossard P, et al. Genomewide association study in individuals of south Asian ancestry identifies six new type 2 diabetes susceptibility loci. Nat Genet. 2011;43(10):984-9. https://doi.org/10.1038/ng.921.

41. Guan F, Niu Y, Zhang T, Liu S, Ma L, Qi T, et al. Two-stage association study to identify the genetic susceptibility of a novel common variant of rs2075290 in ZPR1 to type 2 diabetes. Sci Rep. 2016;6:29586. https://doi.org/ 10.1038/srep29586.

42. Galcheva-Gargova Z, Gangwani L, Konstantinov KN, Mikrut M, Theroux SJ, Enoch T, et al. The cytoplasmic zinc finger protein ZPR1 accumulates in the nucleolus of proliferating cells. Mol Biol Cell. 1998;9(10):2963-71. https://doi. org $/ 10.1091 / \mathrm{mbc} .9 .10 .2963$

43. Rui XY, Yu MC, Shang LP, Feng PH, Tang WL, De ZY, et al. Effects of demographic, dietary and other lifestyle factors on the prevalence of hyperlipidemia in Guangxi Hei Yi Zhuang and Han populations. Eur J Cardiovasc Prev Rehabil. 2006;13:977-84. https://doi.org/10.1097/01.hjr. 0000239476.79428 .25 .

44. Yin RX, Wu DF, Miao L, Aung LH, Cao XL, Yan TT, et al. Several genetic polymorphisms interact with overweight/obesity to influence serum lipid levels. Cardiovasc Diabetol. 2012;11:123. https://doi.org/10.1186/1475-284011-123.

\section{Publisher's Note}

Springer Nature remains neutral with regard to jurisdictional claims in published maps and institutional affiliations.

Ready to submit your research? Choose BMC and benefit from:

- fast, convenient online submission

- thorough peer review by experienced researchers in your field

- rapid publication on acceptance

- support for research data, including large and complex data types

- gold Open Access which fosters wider collaboration and increased citations

- maximum visibility for your research: over $100 \mathrm{M}$ website views per year

At BMC, research is always in progress.

Learn more biomedcentral.com/submissions 